\title{
TEM Characterization of C eria Supported Pt Catalyst for Water-Gas Shift Reaction Produced by Reactive Spray Deposition Technique
}

\author{
Rishabh Jain ${ }^{1,4}$, Chung-Hao Kuo ${ }^{3}$, Justin Roller ${ }^{1,4}$, Steven L. Suib ${ }^{3}$, C Barry Carter ${ }^{1,2}$, Radenka \\ Maric $^{1,2,4}$ \\ 1. Department of Materials Science and Engineering, University of Connecticut, 97 North \\ Eagleville Road, Unit 3136 Storrs, CT 06269. \\ 2. Department of Chemical and Biomolecular Engineering, University of Connecticut, 191 \\ Auditorium Road, Unit 3222 Storrs, CT 06269. \\ 3. Department of Chemistry, University of Connecticut, 55 North Eagleville Road, Unit 3060 \\ Storrs, CT 06269. \\ 4. Center for Clean Energy Engineering, University of Connecticut, 44 Weaver Road, Unit 5233 \\ Storrs CT 06269.
}

The water-gas shift reaction (WGSR) $\left(\mathrm{CO}(\mathrm{g})+\mathrm{H}_{2} \mathrm{O}(\mathrm{g}) \rightarrow \mathrm{CO}_{2}(\mathrm{~g})+\mathrm{H}_{2}(\mathrm{~g})\right)$ is among the most expensive fuel processing unit operations, due to the equilibrium limitations and slow kinetics on commercial $\mathrm{Cu}$-based catalysts. $\mathrm{Pt}, \mathrm{Pd}$, and $\mathrm{Rh}$ supported on ceria had specific WGS reaction rates (normalized to the catalyst area) identical for each of the metals and much higher than those for either pure ceria or each of the precious metals supported on alumina. The water-gas shift on ceria-supported precious metals occurs through a bi-functional redox mechanism in which $\mathrm{CO}$ adsorbed on the precious metal is oxidized by ceria, which, in turn, is oxidized by water ${ }^{1,2}$. Ceria plays a crucial role in the activation of water through a redox mechanism ${ }^{3}$. In an attempt to determine the factors underlying their higher activity, and to use such knowledge in the design of next-generation WGSR catalysts, we consider these and other metal-support systems within a materials informatics scheme composed of ab initio computations and kinetic modeling coupled with catalysts synthesis, characterization, and testing. Present study is going to investigate the effect of ceria decorated with Pt nanoparticles as the catalyst for WGSR using a one-step flame spray pyrolysis also called reactive spray deposition technique (RSDT). TEM characterization of the ceria and Pt formation will be discussed.

RSDT is a one-step vapor deposition technique to produce novel catalyst materials using flame combustion. A Pt metal salt such as platinum acetylacetonate is dissolved in a high enthalpy solvent such as xylene and blended with $20 \mathrm{wt}$. \% liquefied propane in a sealed pressure vessel. This precursor mixture is sent to a nozzle assembly consisting of a tube of decreasing diameter and preheated to $190 \mathrm{degC}$ by means of an induction coil. The precursor solution exits as a fine spray from the nozzle and is combusted with the help of a set of methane and oxygen pilot lights. The Pt salt from the precursor solution is decomposed to produce Pt in melted form and finally in vapor form. For the catalyst support, a ceria ink is prepared with the suspension of ceria in methanol with Nafion ${ }^{\circledR}$ as a binder and sprayed by a set of slurry nozzles in the reaction zone of the flame. This Pt vapor is condensed on the ceria particles and the resulting ceria supported Pt particles are collected on a substrate, mounted on a platform which moves along an $\mathrm{x}-\mathrm{y}-\mathrm{Z}$ system directed in front of the flame. 
TEM sample preparation is relatively straight forward for RSDT. Five lacey f/c, 200 mesh $\mathrm{Cu}$ grids were mounted on an aluminum grid holder which was built in-house. This holder was placed on the $x-y-z$ platform and introduced directly in front of the flame. The grids were removed at a regular interval of time (say $30 \mathrm{~s}, 60 \mathrm{~s}, 80 \mathrm{~s}, 110 \mathrm{~s}, 180 \mathrm{~s}$ ). No other treatment was done and the grids were introduced directly in the TEM chamber.

The catalysts thus prepared were tested for $\mathrm{CO}$ oxidation in a $10 \% \mathrm{CO}-\mathrm{O}_{2}$ environment. The results are plotted as shown in fig 1 . Primary testing reveals that adding $1 \% \mathrm{Pt}$ on ceria decreased the temperature for complete $\mathrm{CO}$ oxidation from $520 \operatorname{degC}$ to $125 \mathrm{degC}$.

\section{References:}

1. Hyun-Seog Roh et.al, Catal. Lett. 141(1), 95-99 (2011).

2. C Wheeler et.al, J. Catal. 223(1), 191-199 (2004).

3. T. Bunluesin et.al, Appl. Catal. 15(1), 107-114 (1998).

The authors would like to acknowledge support from University of Connecticut for this work.
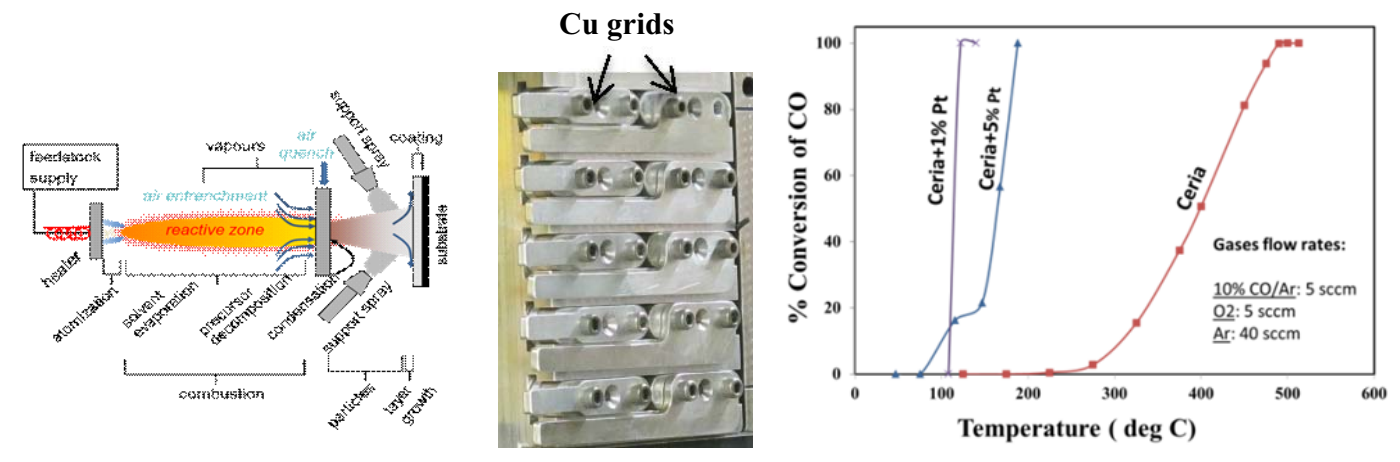

Figure 1. Left: Schematic of RSDT process. Center: A TEM grid holder consisting of different channels for holding individial grids. Right: Effect of Pt loading on CO conversion efficiency of catalysts.
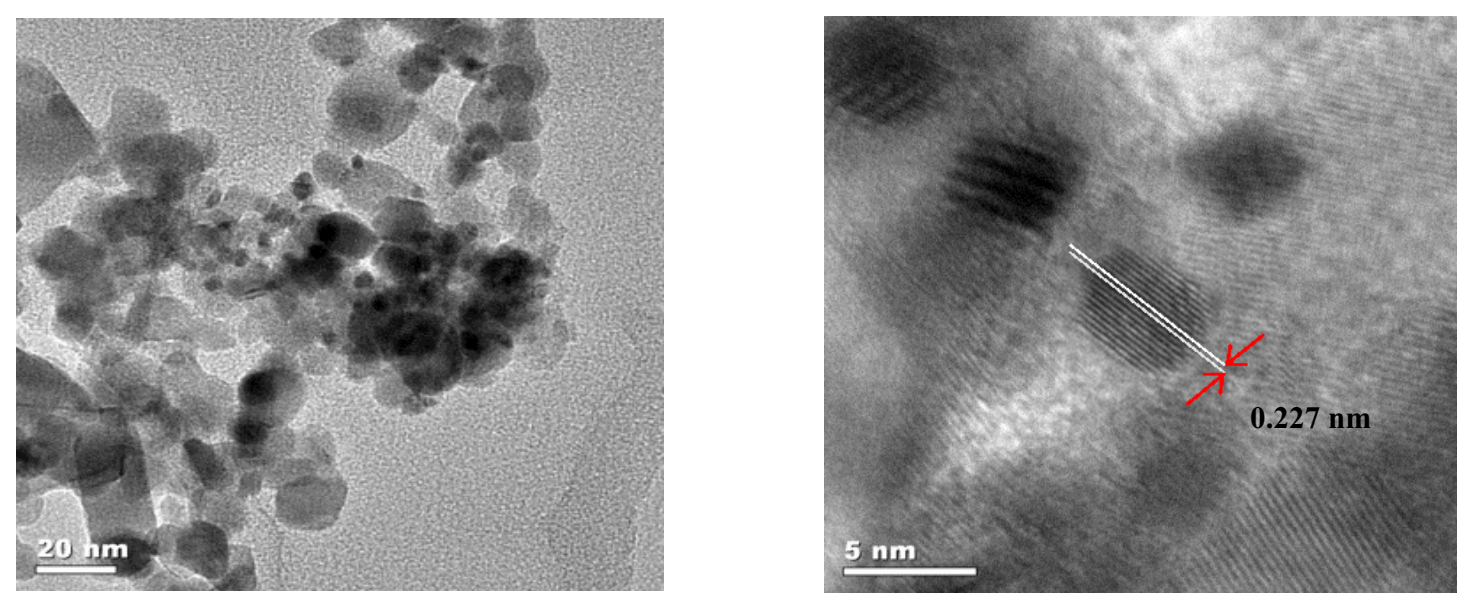

Figure 2. Left: Pt particles on ceria. Right: TEM micrograph showing lattice fringes of a Pt nanoparticle. 